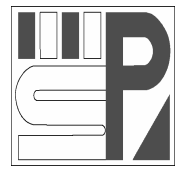

Science Press
Journal of Arid Land

2012, 4(3): 300-309

doi: 10.3724/SP.J.1227.2012.00300

jal.xjegi.com; www.chinasciencejournal.com

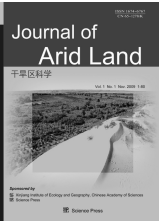

\title{
Simulating the vegetation-producing process in small watersheds in the Loess Plateau of China
}

\author{
KaiBo WANG ${ }^{1}$, ZhouPing SHANGGUAN ${ }^{2 *}$ \\ ${ }^{1}$ State Key Laboratory of Loess and Quaternary Geology, Institute of Earth Environment, Chinese Academy of Sciences, Xi'an \\ 710075, China; \\ ${ }^{2}$ Northwest Agriculture and Forestry University, Yangling 712100, China
}

\begin{abstract}
Small watersheds are the basic composition unit of the Loess Plateau in China. An accurate estimation of vegetation net primary productivity (NPP) is of great significance for eco-benefit evaluation in small watershed management in this region. Here we describe the development and testing of a vegetation-producing process model (VPP) of a small watershed in the Loess Plateau. The model couples three modules: radiation adjustment; soil hydrological processes; and vegetation carbon assimilation. Model validation indicates that the VPP model can be used to estimate the NPP of small watersheds in the region. With the VPP model, we estimated the spatial NPP distributions in the Yangou watershed for 2007. The results show that in the Yangou watershed the NPP is relatively low, averaging $168 \mathrm{~g} \mathrm{C} /\left(\mathrm{m}^{2} \cdot a\right)$. Trees and shrubs have a higher NPP than crops and grasses. The NPP is larger on the partly shaded and shaded slopes than on the partly sunny and sunny slopes. The NPP on the slopes increases gradually on $0-20^{\circ}$ slopes and decreases slightly on slopes steeper than $20^{\circ}$. Our simulation indicates that the vegetation type is the most important factor in determining the NPP distribution in small watersheds in the Loess Plateau.
\end{abstract}

Keywords: small watershed; net primary productivity; vegetation-producing process model; solar radiation; soil hydrological process; vegetation carbon assimilation

Ecosystem degradation due to soil erosion is one of the most serious environmental problems facing human beings (Pimentel, 2006; Zuazo and Pleguezuelo, 2008). Soil erosion is also the key issue that constrains ecological restoration and sustainable agriculture in the Loess Plateau region of China (Liu, 1999). Establishment of vegetation has been shown to be the most positive and effective measure in controlling soil erosion (Shangguan et al., 2004; Zheng, 2006; Zuazo and Pleguezuelo, 2008). Therefore, afforestation and increase in vegetation coverage have become the most important considerations in soil conservation and ecosystem restoration in the Loess Plateau region of China.

The net primary productivity (NPP) of vegetation is a measure of the interaction between vegetational biological characteristics and external environmental fac- tors, and reflects the yielding and adaptive capacity of plant communities. NPP is closely linked to the carbon cycle, climate and land use changes and ecosystem recovery assessment, and characterizes the regional producing and carrying capacity (Nemani et al., 2003; Xia and Shao, 2008; Xu et al., 2009; Arneth et al., 2010). It follows that research projects on NPP are important foundations for ecological restoration and a range of other environmental issues.

NPP is the balance between carbon gained by gross primary productivity (GPP) and carbon lost from the respiration of all plant parts. It is determined not only by the biological characteristics but also the surrounding environmental conditions of plants, including solar energy, temperature, soil nutrition and moisture. In a

Received 2011-10-13; accepted 2012-03-19

*Corresponding author: ZhouPing SHANGGUAN (E-mail: shangguan@ms.iswc.ac.cn) 
small area of a few hectares, NPP can be determined by field measurements. Direct NPP measurement over large areas is difficult, however, and model simulation is suggested as an effective method (Potter et al., 1993; Cramer et al., 1999; Li et al., 2004; Piao et al., 2008). Since the implementation of the International Biological Program (IBP) in the 1960s, a large number of NPP models have been developed for estimating regional and global NPP, such as CASA (Carnegie-Ames-Stanford Approach) (Potter et al., 1993), TEM (Terrestrial Ecosystem Model) (Melillo et al., 1993), BEPS (Boreal Ecosystem Productivity Simulator) (Liu et al., 1997). These models have produced great achievements in simulating regional and global NPP and clarifying the distribution and magnitude of regional and global carbon sources and sinks, and in evaluating the response of terrestrial ecosystems to global changes. However, these models cannot accurately simulate NPP in relatively small watersheds since they do not consider in detail the site features of different ecosystems and thus ignore environmental spatial heterogeneity. As a result, they either overestimate or underestimate the NPP in small watersheds, particularly those with complex terrains. However, small watersheds are the basic composition unit of the Loess Plateau and also the unit for ecological management and soil conservation. It is therefore of great theoretical and practical significance for the evaluation of vegetation restoration and watershed ecosystem management in the Loess Plateau.

An accurate NPP estimation is significant for correctly summarizing the outcome and lessons in watershed management and providing reference and guidance for subsequent watershed management steps in the Loess Plateau. In addition, it will provide a useful tool for predicting NPP responses in the Loess Plateau under future climate and land use conditions. The major objective of this study is to develop and test a vegetation-producing process model (VPP) that includes the effects of terrain and is appropriate for small watersheds in the Loess Plateau.

\section{Model development}

\subsection{Model structure}

The VPP model comprises three modules: topographic correction of solar radiation, simulation of soil hydrological process, and vegetation carbon assimilation (Fig. 1).

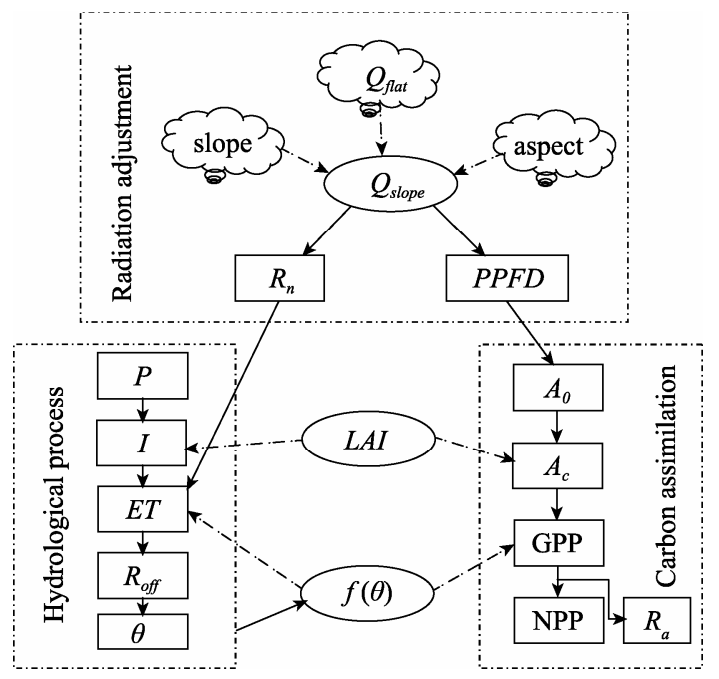

Fig. 1 Structure of the VPP model. The rectangles represent primary process variables; the ovals represent key variables influencing or linking the hydrological process and carbon assimilation; and the cloud-shaped boxes represent the parameters impacting the slope solar radiation. The solid lines represent energy, water and carbon flow directions and the dashed lines denote the effects of environmental variables. $Q_{f l a t}$, solar radiation on flat terrains; $Q_{\text {slope }}$, solar radiation on slope land; $R_{n}$, net solar radiation; PPFD, photosynthetically active radiation photon flux; $P$ precipitation; I, canopy interception; $E T$, evapotranspiration; $R_{\text {off, }}$, surface runoff; $\theta$, mean soil moisture content at depths of $0-2 \mathrm{~m}$; $L A l$, leaf area index; $f(\theta)$, soil-water stress coefficient; $A_{0}$, leaf photosynthetic rate; $A_{c}$, canopy photosynthesis; GPP, gross primary productivity; NPP, net primary productivity; $R_{\mathrm{a}}$, total respiration.

We constructed a solar radiation distribution model based on the digital elevation model (DEM) of the study area in line with the complex terrain features of hilly loess regions in China. Using flatland solar radiation as a base, we integrated the effect of slope and aspect to simulate solar radiation for the hilly areas. For the hydrological and carbon assimilation process modules, leaf area index $(L A I)$ and soil-water stress coefficient $(f(\theta))$ are the two key variables that connect soil-water balance and vegetation primary production. The hydrological processes in the Loess Plateau mainly consist of precipitation, interception, evapotranspiration, surface runoff, and variations in soil 
water storage. Changes of variables in the water balance equation can induce variation in the soil water content, thereby affecting the physiological and ecological processes in plant and altering the primary production of vegetation. Carbon assimilation at leaf level in the VPP model is simulated using the hyperbolic equation developed by Prioul and Chartier (1977), scaled-up to the canopy level by the big-leaf model (Sellers et al., 1992) for the relatively less and easily obtained variables. Finally, the NPP is computed as the difference between total plant respiration and gross primary production.

\subsection{Model description}

The model is driven by meteorological, soil, biological and spatial raster data. The detailed input data are given as follows: (1) Meteorological data (daily maximum, minimum and average temperatures, precipitation, relative humidity, solar radiation, sunshine hours, and average wind speed); (2) Spatial raster data (maps of vegetation type, slope, and aspect); (3) Vegetation physiological and ecological parameters (average plant height, community coverage, plant phenology, plant photosynthetic characteristic parameters, and initial biomass of each plant component); (4) Soil property parameters (soil bulk density, soil field capacity, wilting water content, and initial soil moisture content).

The model runs at a daily time step with the grid size of $20 \mathrm{~m} \times 20 \mathrm{~m}$. Simulation results can be exported for time steps of per day, per month and per year. Output includes slope solar radiation $\left(Q_{\text {slope }}\right)$, net solar radiation $\left(R_{n}\right)$, photosynthetically active radiation $\left(Q_{p a r}\right)$, mean soil moisture content at the depth of 0-2 m, evapotranspiration $(E T)$, runoff $\left(R_{o f f}\right)$, canopy interception $(I)$ and leaf area index $(L A I)$, and the $G P P, N P P$, maintenance and growth respiration $\left(R_{m}, R_{g}\right)$ of the vegetation.

The detailed calculation method and process of the model are described below.

\subsubsection{Solar radiation}

Solar radiation is the most important variable in NPP simulation as it controls the energy balance of the watershed, thus deeply influencing the soil water balance. It is the energy source of plant photosyn- thesis and drives the ecosystem carbon cycle. In flat terrains, the solar radiation measured at one point can be extrapolated over a large area virtually unchanged. In complex terrain, however, the spatial variability in elevation, slope and aspect can create very strong local gradients in solar radiation that can induce large-scale variation in vegetation productivity. In the VPP model, we considered the effect of slope and aspect on solar radiation but not the effect of altitude, since the study area possesses complex terrains but relatively small differences in elevation.

Solar radiation in complex terrains is termed 'slope solar radiation' $\left(Q_{\text {slope }}\right)$ as opposed to solar radiation in flat terrains $\left(Q_{\text {flat }}\right)$ derived from meteorological data. $Q_{\text {slope }}$ calculation was based on the hypothesis that the ratio of solar radiation to extraterrestrial radiation in flat terrains is equal to the ratio of the slope solar radiation to the slope extraterrestrial radiation over the slope (Zeng et al., 2005):

$$
Q_{\text {slope }}=Q_{\text {flat }} \times \frac{R_{\text {flat }}}{R_{\text {slope }}} .
$$

Where, $R_{\text {flat }}$ and $R_{\text {slope }}$ are the horizontal extraterrestrial radiation and slope extraterrestrial radiation, respectively.

The values of $R_{\text {flat }}$ and $R_{\text {slope }}$ were calculated by Eqs. 2 and 3 (Allen et al., 1998; Fu, 1998), and $\omega_{s 1}$ and $\omega_{s 2}$ in Eq. 3 were calculated after $\mathrm{Fu}$ (1998):

$$
\begin{aligned}
R_{\text {flat }}= & \frac{24 \times 60}{\pi} G_{s c} d_{r} \\
& \times\left(\omega_{s} \sin \phi \sin \delta+\cos \phi \cos \delta \cos \omega_{s}\right), \\
R_{\text {slope }}= & \frac{24 \times 60}{\pi} G_{s c} d_{r} u \sin \delta \times\left(\omega_{s 2}-\omega_{s 1}\right) \\
& +v \cos \delta \times\left(\sin \omega_{s 2}-\sin \omega_{s 1}\right) \\
& -w \cos \delta \times\left(\cos \omega_{s 2}-\cos \omega_{s 1}\right) .
\end{aligned}
$$

Where, $G_{s c}$ is the solar constant $(\mathrm{MJ}(\mathrm{m} \cdot \mathrm{min})) ; d_{r}$ is the inverse relative Earth-Sun distance (dimensionless); $\varphi$ is the latitude of the study area ( $\mathrm{rad}) ; \delta$ is the solar decimation (rad); $\omega_{s 1}$ and $\omega_{s 2}$ are the sunrise hour angle (rad) and the sunset hour angle (rad) of slope land, respectively; and $u, v$ and $w$ are the intermediate variables which were calculated after $\mathrm{Fu}$ (1998).

After calculating $Q_{\text {slope }}$, the net radiation $\left(R_{n}\right)$ on the slope surface was obtained from Eqs. 4-6, and the 
photosynthetically active radiation $\left(Q_{p a r}\right)$ and photosynthetically active radiation photon flux (PPFD) were computed by Eqs. 7 and 8 (Zhou et al., 1984):

$$
\begin{gathered}
R_{n}=R_{n s}-R_{n l}, \\
R_{n s}=Q_{\text {slope }} \times\left(1-C_{r}\right), \\
R_{n l}=\sigma\left(\frac{T_{\max }^{4}+T_{\min }^{4}}{2}\right) \times\left(0.34-0.14 \sqrt{e_{a}}\right) \\
\times\left(1.35 \frac{n}{N}-0.35\right), \\
Q_{p a r}=Q_{\text {slope }}\left(0.384+0.053 \log e_{a}\right), \\
P P F D=\frac{4.57 \times 10^{6} Q_{p a r} .}{3600 \times n} .
\end{gathered}
$$

Where, $R_{n s}$ and $R_{n l}$ are the net shortwave radiation $\left(\mathrm{MJ} /\left(\mathrm{m}^{2} \cdot\right.\right.$ day $\left.)\right)$ and net long wave radiation $\left(\mathrm{MJ} /\left(\mathrm{m}^{2} \cdot\right.\right.$ day)); $C_{r}$ is the Albedo (dimensionless); $T_{\max }$ and $T_{\min }$ are the maximum absolute temperature $(\mathrm{K})$ and minimum absolute temperature $(\mathrm{K})$, respectively; $\sigma$ is the Stefan-Boltzmann constant $\left(\mathrm{MJ} / \mathrm{K}^{4} /\left(\mathrm{m}^{2} \cdot\right.\right.$ day $\left.)\right)$; $e_{a}$ is the actual vapor pressure $(\mathrm{kPa}) ; n$ is the actual daylight hours; and $N$ is the theoretical daylight hours.

\subsubsection{Soil-water balance}

In the arid and semi-arid Loess Plateau region of China, precipitation is the main source of soil moisture. Also, in most areas the water table is deep and the unsaturated soil layer may be up to tens of meters thick, so that almost no deep leakage occurs (Yang and Shao, 2000). Therefore, according to the principle of soil-water balance, the variation in soil water content was calculated as follows:

$$
\Delta \theta=P-I-E T-R_{\text {off }} \text {. }
$$

The variables for the soil-water balance equation were calculated from Eqs. 10-16 in which the precipitation $(P)$ was obtained from meteorological data, the canopy interception $(I)$ was calculated according to $\mathrm{Xu}$ et al. (2005), the modified SCS-CN model was used to calculate the surface runoff $\left(R_{o f f}\right)$ (Liu et al., 2005), and the FAO Penman-Monteith equation was used to calculate the evapotranspiration (ET) (Allen et al., 1998).

In most areas of the Loess Plateau the potential evaporation is about $800-1,000 \mathrm{~mm}$ per year, while the average yearly precipitation is about $400-600 \mathrm{~mm}$
(Li, 2001). As the amount of precipitation is far from meeting the demand of evapotranspiration in the region, we have introduced a soil-water stress coefficient $(f(\theta))$ into the calculation of the evapotranspiration for the watershed. $f(\theta)$ is shown as Eq. 15 (Xia and Shao, 2008).

$$
\begin{gathered}
I=\left\{\begin{array}{ll}
P & P<S_{v}, \\
S_{v} & P \geq S_{v}
\end{array},\right. \\
S_{v}=I_{\max }\left[\begin{array}{ll}
1-\exp (-0.5 L A I)], \\
R_{\text {off }}=\frac{(P-0.2 S) \times(P-0.2 S)}{P+0.8 S} & P \geq 0.2 S, \\
R_{\text {off }}=0 & P<0.2 S
\end{array}\right. \\
S=\frac{25400}{C N}-254, \\
E T=K_{c} \times f(\theta) \times E T_{0}, \\
f(\theta)= \begin{cases}\frac{\theta-\theta_{r}}{\theta_{f}-\theta_{r}} & \theta_{r} \leq \theta \leq \theta^{*}, \\
0 & \theta \leq \theta_{r}\end{cases} \\
E T_{0}=\frac{0.408 \Delta\left(R_{n}-G\right)+\gamma \frac{900}{T+273} u_{2}\left(e_{s}-e_{a}\right)}{\Delta+\gamma\left(1+0.34 u_{2}\right)} .
\end{gathered}
$$

Where, $S_{v}$ is the water storage capacity of vegetation canopy $(\mathrm{mm}) ; I_{\max }$ is the maximum interception of vegetation (mm); $S$ is the potential maximum retention after the beginning of runoff (mm); $C N$ is the curve number (dimensionless); $K_{\mathrm{c}}$ is the crop coefficient (dimensionless); $\theta_{f}$ and $\theta_{r}$ are respectively the field capacity $(\mathrm{mm})$ and wilting water content $(\mathrm{mm}) ; \theta^{*}$ is the critical water content when plant suffered soil water stress $(\mathrm{mm}) ; G$ is the soil heat flux density $\left(\mathrm{MJ} /\left(\mathrm{m}^{2} \cdot\right.\right.$ day $\left.)\right) ; T$ is the daily average air temperature $\left({ }^{\circ} \mathrm{C}\right) ; u_{2}$ is the wind speed at $2-\mathrm{m}$ height $(\mathrm{m} / \mathrm{s}) ; e_{s}$ is the saturation vapor pressure $(\mathrm{kPa}) ; \Delta$ is the slope vapour pressure curve $\left(\mathrm{kPa} /{ }^{\circ} \mathrm{C}\right)$; and $\gamma$ is the psychrometric constant $\left(\mathrm{kPa} /{ }^{\circ} \mathrm{C}\right)$.

\subsubsection{Carbon cycling}

(1) Leaf area index (LAI)

$L A I$ is another key variable in the VPP model in that it has a significant effect on both the hydrological process and carbon cycle of the watershed. It changes the 
precipitation distribution by canopy interception, impacts the quantum and allocation ratios of evaporation and transpiration, and influences the light interception, thus deeply affecting the simulated carbon assimilation and primary productivity of vegetation.

We assumed that $L A I$ was a function of plant growth stages in the VPP model. It was computed as the product of the $Q$ functions $\left(Q_{f}\left(t_{d}\right)\right)$ and the feature leaf area index (maximum $L A I, L A I_{\max }$ ) for each vegetation type; the definition and detailed calculation process of $Q$ functions were found in Gao (2003). The $L A I_{\max }$ was calculated using an empirical regression equation based on the measured data in the hilly Loess Plateau region (Huang, 2003):

$$
L A I=L A I_{\max } \times Q_{f}\left(t_{d}\right) .
$$

(2) Leaf photosynthesis

We used the hyperbolic equation of light response curve developed by Prioul and Chartier (1977) to compute the instantaneous leaf photosynthesis (Eq. 18). The hyperbolic equation has some physical meaning and it is much simpler than Faquhar's model (Farquhar et al., 1980). The photosynthetic characteristic parameter used in the hyperbolic equation can be easily obtained by measuring the photosynthetic light response curve. The only variable needed to run the model is the photosynthetically active radiation photon flux (PPFD). Leaf photosynthetic rate is affected not only by air temperature and soil moisture, but also by the plant growth stage. As the photosynthetic characteristic parameter in Eq. 18 was measured in July (the period of most vigorous plant growth in the Loess Plateau), in addition to the temperature and soil moisture stress function, we introduced a seasonal correction factor for photosynthesis, $k_{a}$, defined as the ratio of the mean leaf photosynthetic rate to the maximum leaf photosynthetic rate during the relevant period, to co-determine the actual leaf photosynthetic rate (Eq. 19):

$$
\begin{gathered}
A_{0}=\left(\Phi \cdot P P F D+A_{\max }\right) / 2 k-R_{d}- \\
\sqrt{\left(\Phi \cdot P P F D+A_{\max }\right)^{2}-4 \cdot \Phi \cdot P P F D \cdot k \cdot A_{\max }} / 2 k, \\
A=k_{a} \times A_{0} \times f(T) \times f(\theta) .
\end{gathered}
$$

Where, $A_{0}$ is leaf photosynthetic rate; $\Phi$ is the apparent quantum yield; $A_{\max }$ is the leaf saturated photosynthetic rate $\left(\mu \mathrm{mol} /\left(\mathrm{m}^{2} \cdot \mathrm{s}\right)\right) ; k$ is the curvature of the hyperbolic equation; $R_{d}$ is the dark respiration of the plant $\left(\mu \mathrm{mol} /\left(\mathrm{m}^{2} \cdot \mathrm{s}\right)\right) ; f(T)$ is the temperature stress function (dimensionless); $f(\theta)$ was computed by Eq. 15.

(3) Canopy photosynthesis

The VPP model is capable of simulating daily NPP variations; but since our main aim was to simulate the annual average NPP, we adopted the big-leaf model of canopy photosynthesis simulation in order to simplify the overall model (Sellers et al., 1992). The big-leaf model assumes that canopy carbon fluxes have the same relative responses to the environment as an individual leaf, and that scaling from leaf to canopy is therefore linear. The canopy photosynthesis $\left(A_{c}\right)$ was calculated by:

$$
A_{c}=\int_{0}^{L A I} A(L) d L=\int_{0}^{L A I} A \times e^{-K L} d L=\frac{1-e^{-K \times L A I}}{K} A .
$$

The daily gross primary productivity (GPP) was calculated by Eq. (21):

$$
G P P=A_{c} \times n \times 12.01 \times 10^{-6} \text {. }
$$

Where, $n$ is the sunshine hours; 12.01 is the molar mass of carbon atoms $(\mathrm{g} / \mathrm{mol})$, and $10^{-6}$ is the unit conversion factor from $A_{c}\left(\mu \mathrm{mol} /\left(\mathrm{m}^{2} \cdot \mathrm{s}\right)\right)$ to $G P P(\mathrm{~g} \mathrm{C} /$ $\left(\mathrm{m}^{2} \cdot\right.$ day $\left.)\right)$.

Vegetation uses the GPP partly to maintain its growth needs, the remainder being consumed by growth and maintenance respiration. The NPP of vegetation was estimated by subtracting the total respiration $\left(R_{a}=R_{m}+R_{g}\right)$ from the GPP (Eq. 22):

$$
\begin{gathered}
N P P=G P P-R_{m}-R_{g}, \\
R_{m}=\sum R_{m i}^{25} Q_{10}^{0.1\left(T_{c}-25\right)} \times M_{i}, \quad(i=l, s, r), \\
R_{g}=r \times G P P .
\end{gathered}
$$

Where, $R_{m}$ is maintenance respiration $\left(\mathrm{g} \mathrm{C} /\left(\mathrm{m}^{2} \cdot\right.\right.$ day $\left.)\right)$; $R_{g}$ is growth respiration $\left(\mathrm{g} \mathrm{C} /\left(\mathrm{m}^{2} \cdot\right.\right.$ day $\left.)\right) ; R_{m i}^{25}$ is the maintenance respiration coefficient; $Q_{10}$ is the temperature sensitivity factor; $T_{c}$ is canopy temperature $\left({ }^{\circ} \mathrm{C}\right) ; M_{i}$ is the initial biomass of the plant $\left(\mathrm{g} / \mathrm{m}^{2}\right)$; and $r$ is the growth respiration coefficient (dimensionless).

\section{Model validation and application}

The VPP model was developed and validated in the Yangou watershed, located in the central Loess Plateau of China $\left(109^{\circ} 20^{\prime}-109^{\circ} 35^{\prime} \mathrm{E}, 36^{\circ} 28^{\prime}-36^{\circ} 32^{\prime} \mathrm{N}\right.$; Fig. 2); 
the region is $8.6 \mathrm{~km}$ in length, and covers an area of about $47 \mathrm{~km}^{2}$. The landform is typical hilly loess, at an elevation of $980-1,400 \mathrm{~m}$. It has a semi-arid continental climate, with an annual mean precipitation of 560 $\mathrm{mm}$ and an average temperature of $9.8^{\circ} \mathrm{C}$. The soil is calcareous silt loam (calcic Cambisol) belonging to the Entisol order (USDA texture classification system), derived from loess to depths generally beyond $50 \mathrm{~m}$.

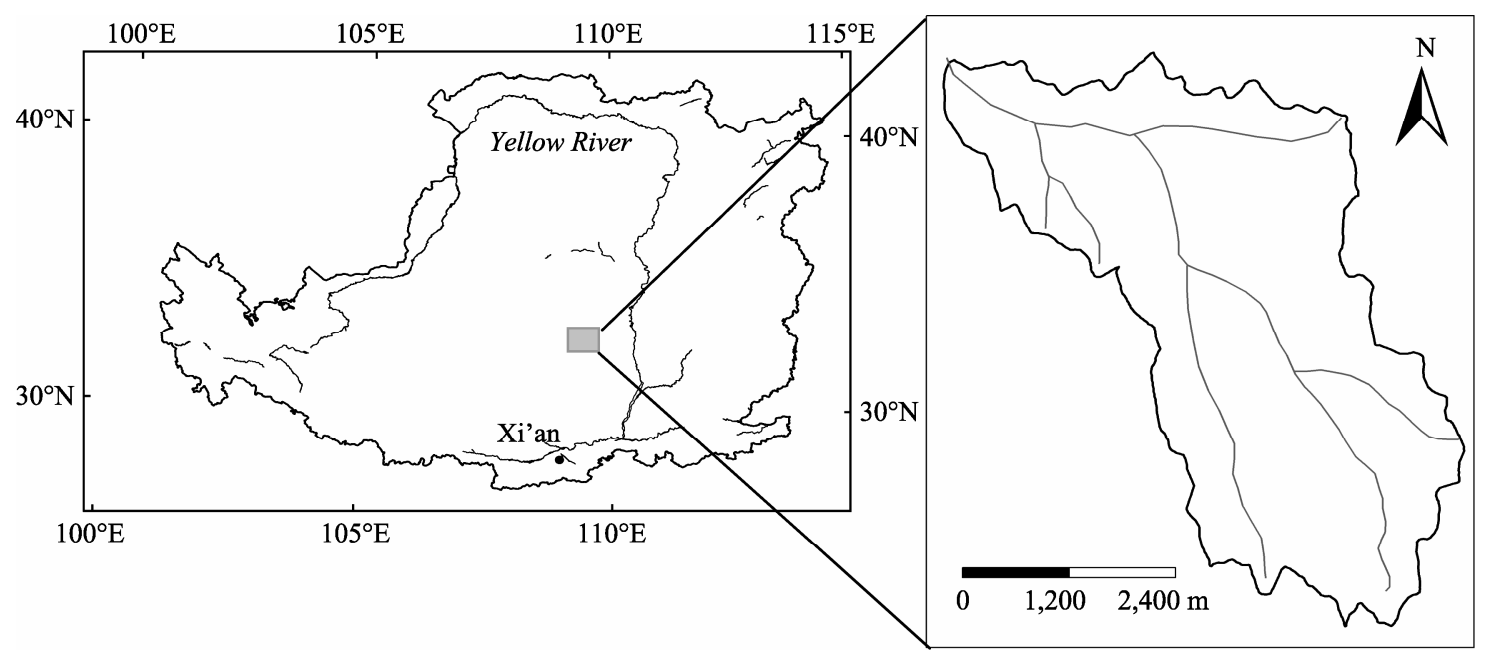

Fig. 2 Location of Yangou watershed in the Loess Plateau of China

The natural biome is the northern extended area of deciduous broadleaf forest and the zonal climax vegetation is oak forest dominated by Quercus liaotungensis. Robinnia pseudoscacia and Populus spp. are the main plantation tree species that account for $18.6 \%$ of the total watershed area (Wang et al., 2008). Sophora davidii, Caragana and Spiraea schneideriana are the main shrub species. Artemisia sacrorum and Artemisia giraldii are the main herb species. In addition, crops such as maize and millet are widely planted on the flatlands and terraces; apple trees are mainly distributed over the hilltops and upper slopes.

The values of the parameters used in the VPP model were obtained either by field measurements or from published sources. The climate data were gathered from Yan'an meteorological station, about $3 \mathrm{~km}$ from the study area. Since, as stated above, the area of the watershed is only $47 \mathrm{~km}^{2}$, we were able to ignore the spatial variation in meteorological elements such as precipitation and temperature. However, the effects of topography on solar radiation were taken into account, and we established a distributed solar radiation model based on the DEM of the study area. The vegetation-type map was digitized based on the land use map of the Yangou watershed produced in 2007. The slope and aspect maps were created from the DEM of the watershed using Arcgis 9.3 (ESRI, Inc., Redlands, USA). As more than $90 \%$ of the watershed is covered by loess, we assumed homogeneous soil properties: bulk density is $1.25 \mathrm{~g} / \mathrm{m}^{3}$, field capacity is $24.3 \%$, and wilting moisture is $6.3 \%$ (Yang and Shao, 2000). Soil moisture content was measured at the $0-2 \mathrm{~m}$ depth for the different vegetation types in late May, July and September of 2007. Five widely distributed species were chosen to represent different vegetation types in the watershed: Robinnia pseudoscacia (tree), Caragana microphylla (shrub), Artemisia sacrorum (grass), Malus pumila (orchard) and Zea mays (crop). Related physiological and ecological parameters of the five vegetation types were measured to drive and validate the model. The leaf area index was measured with a LAI-2000 plant canopy analyzer (LI-COR, Inc., Lincoln, USA) and the above-ground biomass was harvested to validate the NPP. The initial soil and vegetation parameters for the study area used in the model were obtained from both published reports and field observations (Liu, 2003; Li et al., 2004; He et al., 2005; Piao et al., 2005; Wu et al., 2005; Xu et al., 2005).

At present, the validation of NPP models poses major difficulties on a regional and global scale, and it is also difficult at the watershed scale. In this study, 
we tested the VPP model through comparing field measurements and the results obtained by a selection of other relevant models. Figure 3 shows the aboveground NPP for different communities in 2007, together with previously published data (Liu, 2003; Li et al., 2004; Wu et al., 2005; Xu et al., 2005). Because the NPP measurements of the five land-cover types were carried out on different stand ages and site conditions, a large difference is evident between the measured maximum and minimum NPP values and the simulated mean NPP values. However, the simulated and observed mean NPP values were highly consistent (Fig. 3), with a relative error of less than $10 \%$.

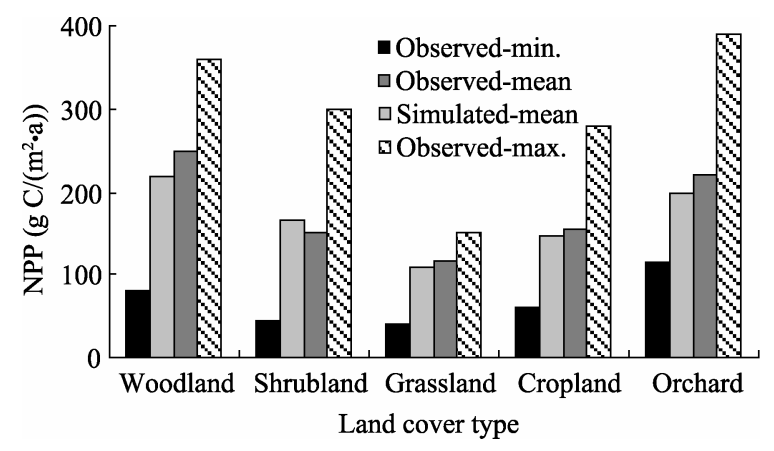

Fig. 3 Observed and simulated NPP for the different land cover types in the study area. The observed NPPs of the woodland, shrubland and orchard land were mainly obtained from $\mathrm{Xu}$ et al. (2005); and the NPPs of the grassland and cropland were obtained based on our field measurement.

Table 1 shows the average annual NPP estimated by the different models. The NPP simulated by our model was close to that by VSIM (Vegetation-Soil Integrated Model; Xu et al., 2005) but less than those of CASA (Carnegie-Ames-Stanford Approach; Piao et al., 2005), AVIM (Atmosphere-Vegetation Interaction Model; He et al., 2005) and CEVSA (Carbon Exchange between Vegetation, Soil, and the Atmosphere; Li et al., 2004) which gave the average NPP for different vegetation types of China, probably because these models were originally developed for large-scale simulation. The VSIM model was developed for small watersheds and was validated with appropriate parameters for the hilly loess region (Table 1); it is therefore likely that its estimated NPP value was more accurate for the Loess Plateau. The validation and model comparison on the basis of the measured data indicated that the VPP model was able to estimate the NPP in the Loess Plateau.

Table 1 NPP comparison between the VPP model and the other models

\begin{tabular}{cccccc}
\hline Land cover type & VPP & VSIM & $\begin{array}{c}\text { CASA } \\
\left(\mathrm{g} \mathrm{C}^{\prime}\left(\mathrm{m}^{2} \cdot \mathrm{a}\right)\right)\end{array}$ & AVIM & CEVSA \\
\hline Woodland & 220 & 221 & 245 & 530 & 560 \\
Shrubland & 166 & 140 & 257 & 159 & 120 \\
Grassland & 109 & 65 & 144 & 275 & 270 \\
Cropland & 147 & 175 & 170 & 541 & 606 \\
Orchard & 199 & 190 & - & - & - \\
\hline
\end{tabular}

\section{Results and discussion}

In Yangou watershed, the NPP was between 0 and 300 $\mathrm{g} \mathrm{C} /\left(\mathrm{m}^{2} \cdot \mathrm{a}\right)$, averaging $168 \mathrm{~g} \mathrm{C} /\left(\mathrm{m}^{2} \cdot \mathrm{a}\right)$ (Fig. $\left.4 \mathrm{~b}\right)$. The NPP was significantly different between the different vegetation types. Woodland had the highest NPP averaged $220 \mathrm{~g} \mathrm{C} /\left(\mathrm{m}^{2} \cdot \mathrm{a}\right)$, which was twice that of the grassland; orchard had the second highest NPP which was about $90 \%$ that of the woodland; shrub and cropland had medium NPP which were respectively about $76 \%$ and $68 \%$ that of the woodland (Table 1). Overall, the trees and shrubs had higher NPP values than crops and grasses. The NPP distribution map of the Yangou watershed was highly consistent with its land use map (Fig. 4), indicating that vegetation type was the decisive factor affecting NPP distribution in a small watershed.

At different aspects and on different slopes, the NPP did not differ greatly in the Yangou watershed (Figs. 5, 6). The average NPP at different aspects ranged from 154 to $174 \mathrm{~g} \mathrm{C} /\left(\mathrm{m}^{2} \cdot \mathrm{a}\right)$. The NPP was larger on the partly shaded and shaded slopes than on the partly sunny and sunny slopes. The NPP on the partly sunny slopes was almost equal to the average value of the watershed. The average NPP on the slopes varied between 153 and $176 \mathrm{~g} \mathrm{C} /\left(\mathrm{m}^{2} \cdot \mathrm{a}\right)$, increasing gradually on the $0^{\circ}-20^{\circ}$ slopes, peaking on the $10^{\circ}-20^{\circ}$ slopes, and decreasing slightly on slopes steeper than $20^{\circ}$.

Within a given range, NPP increased with the increase in solar radiation. However, soil water deficit can severely constrain plant growth, thus lowering the NPP, especially in arid and semi-arid regions. The higher level of solar radiation on the sunny and partly sunny slopes resulted in higher evapotranspiration and 


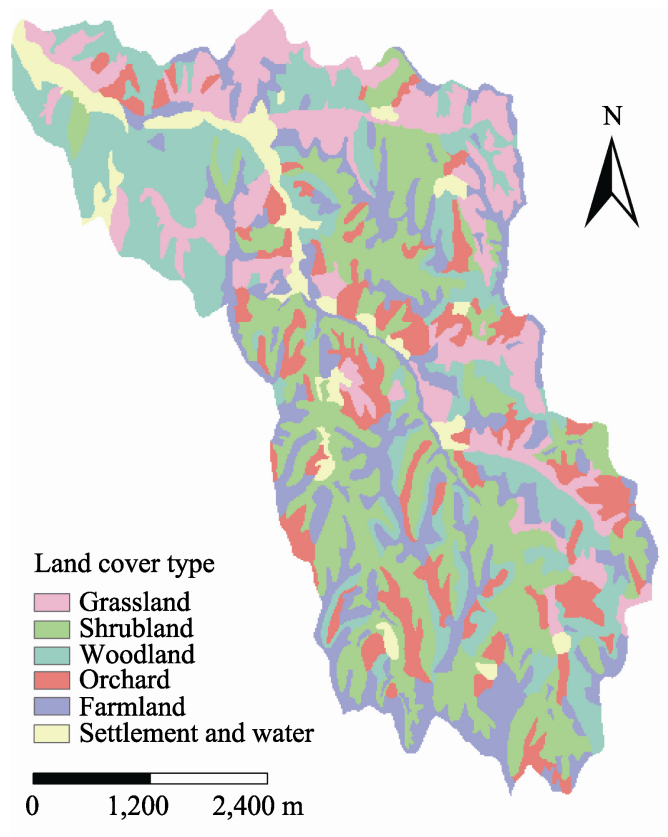

(a) Land use map

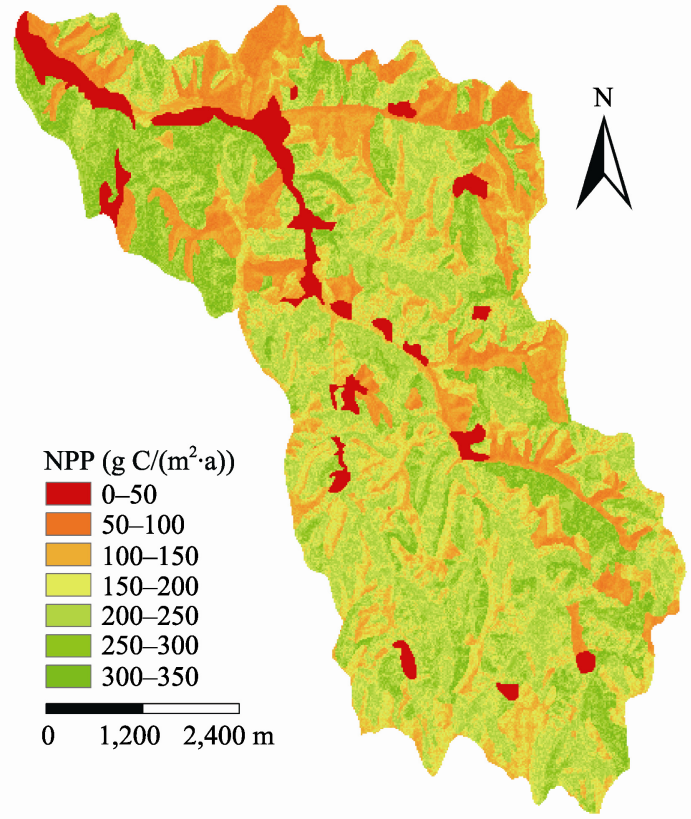

(b) Net Primary Productivity (NPP) distribution map of 2007

Fig. 4 Land use map and NPP map of Yangou watershed in 2007. The land use map was based on interpretation of a TM remote sensing image obtained in the same year. The NPP map was calculated by the VPP model.

lower soil water content, causing lowered NPP compared to shady and semi-shady slopes.

Although the NPP was greatly influenced by variations in solar radiation, soil moisture and other environmental elements on the scale of the site, the spatial distribution pattern of vegetation has an important influence on NPP distribution in the Yangou watershed. The NPPs of the woodland and shrubland were generally much larger than for the cropland and grassland. The forests and shrubs, as the two main vegetation types, were distributed more on the partially shaded

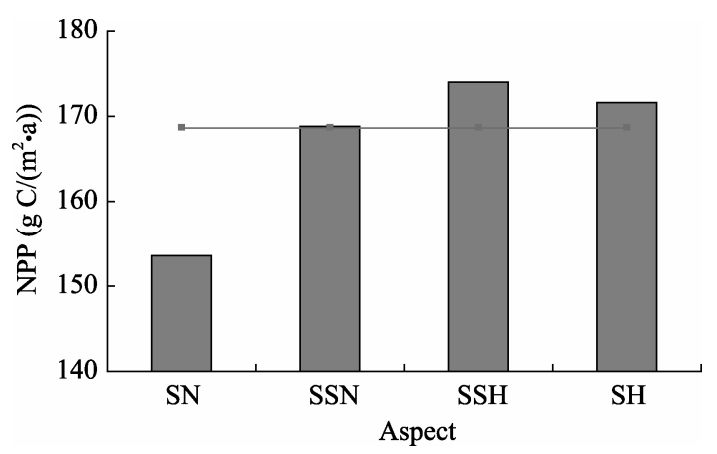

Fig. 5 NPP distribution at different aspects in Yangou watershed in 2007. The dash-dot line represents the average NPP of the watershed. SN, sunny slope; SSN, semi-sunny slope; SSH, semi-shady slope; $\mathrm{SH}$, shady slope.

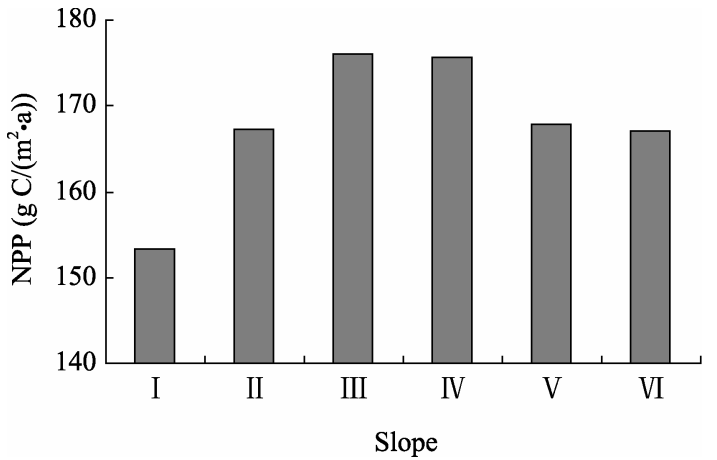

Fig. 6 NPP distribution on different slopes in Yangou watershed in 2007. I , $0^{\circ}-5^{\circ}$; II , $5^{\circ}-10^{\circ}$; III, $10^{\circ}-15^{\circ}$; IV, $15^{\circ}-20^{\circ}$; V, $20^{\circ}-25^{\circ} ; \mathrm{VI},>25^{\circ}$.

slopes than on the sunny slopes, resulting in lower NPP on the sunny slopes than on the partially shaded slopes (Table 2). The distribution of land cover types on different slopes showed that vegetation types changed with slope variation, which probably caused slight differences in NPP for the different slopes. Of the five land cover types, the cropland had the highest distribution percentage on the $<10^{\circ}$ slopes and woodland had the highest distribution percentage on the slopes of $15-20^{\circ}$ (Table 3). These agreed with the NPP distribution on the different slopes. 
Table 2 Distribution of the land cover types at different aspects in Yangou watershed

\begin{tabular}{|c|c|c|c|c|c|c|c|c|c|c|}
\hline \multirow{3}{*}{ Aspect } & \multicolumn{10}{|c|}{ Land cover type } \\
\hline & \multicolumn{2}{|c|}{ Woodland } & \multicolumn{2}{|c|}{ Shrubland } & \multicolumn{2}{|c|}{ Grassland } & \multicolumn{2}{|c|}{ Cropland } & \multicolumn{2}{|c|}{ Orchard } \\
\hline & Area $\left(\mathrm{hm}^{2}\right)$ & Percentage (\%) & Area $\left(\mathrm{hm}^{2}\right)$ & Percentage (\%) & Area $\left(\mathrm{hm}^{2}\right)$ & Percentage (\%) & Area $\left(\mathrm{hm}^{2}\right)$ & Percentage (\%) & Area $\left(\mathrm{hm}^{2}\right)$ & Percentage (\%) \\
\hline $\mathrm{SN}$ & 144.8 & 3.3 & 164.4 & 3.7 & 190.9 & 4.3 & 127.9 & 2.9 & 135.8 & 3.1 \\
\hline SSN & 286.8 & 6.4 & 323.8 & 7.3 & 228.1 & 5.1 & 244.0 & 5.5 & 182.0 & 4.0 \\
\hline $\mathrm{SH}$ & 400.6 & 9.0 & 487.9 & 11.0 & 191.4 & 4.3 & 303.8 & 6.8 & 168.3 & 3.8 \\
\hline SSH & 205.8 & 4.6 & 267.6 & 6.0 & 133.0 & 3.0 & 167.0 & 3.8 & 93.9 & 2.1 \\
\hline WW & $1,038.0$ & 23.3 & $1,243.8$ & 28.0 & 743.3 & 16.7 & 842.7 & 19.0 & 579.9 & 13.0 \\
\hline
\end{tabular}

Note: WW, whole watershed.

Table 3 Distribution of the land cover types on different slopes in Yangou watershed

\begin{tabular}{|c|c|c|c|c|c|c|c|c|c|c|}
\hline \multirow{3}{*}{ Slope $\left({ }^{\circ}\right)$} & \multicolumn{10}{|c|}{ Land cover type } \\
\hline & \multicolumn{2}{|c|}{ Woodland } & \multicolumn{2}{|c|}{ Shrubland } & \multicolumn{2}{|c|}{ Grassland } & \multicolumn{2}{|c|}{ Cropland } & \multicolumn{2}{|c|}{ Orchard } \\
\hline & Area $\left(\mathrm{hm}^{2}\right)$ & Percentage (\%) & Area $\left(\mathrm{hm}^{2}\right)$ & Percentage $(\%)$ & Area $\left(\mathrm{hm}^{2}\right)$ & Percentage (\%) & Area $\left(\mathrm{hm}^{2}\right)$ & Percentage (\%) & Area $\left(\mathrm{hm}^{2}\right)$ & Percentage (\%) \\
\hline $0-5$ & 29.5 & 0.7 & 41.9 & 0.9 & 30.2 & 0.7 & 49.9 & 1.1 & 22.9 & 0.5 \\
\hline $5-10$ & 63.4 & 1.4 & 77.6 & 1.7 & 47.8 & 1.1 & 81.5 & 1.8 & 47.6 & 1.1 \\
\hline $10-15$ & 100.3 & 2.3 & 97.4 & 2.2 & 57.8 & 1.3 & 105.8 & 2.4 & 68.0 & 1.5 \\
\hline $15-20$ & 140.5 & 3.2 & 129.5 & 2.9 & 78.5 & 1.8 & 120.5 & 2.7 & 88.0 & 2.0 \\
\hline $20-25$ & 171.0 & 3.8 & 178.0 & 4.0 & 107.6 & 2.4 & 133.9 & 3.0 & 99.4 & 2.2 \\
\hline$>25$ & 533.3 & 12.0 & 719.4 & 16.2 & 421.4 & 9.5 & 351.1 & 7.9 & 254.0 & 5.7 \\
\hline WW & $1,038.0$ & 23.4 & $1,243.8$ & 27.9 & 743.3 & 16.8 & 842.7 & 18.9 & 579.9 & 13.0 \\
\hline
\end{tabular}

\section{Conclusions}

Taking a small watershed as a unit for soil and water conservation is an important experience of the ecological environment construction in the Loess Plateau. NPP is a critical parameter in evaluating the restoration level of degraded ecosystems and indicating the response of terrestrial ecosystem to global change. Therefore, it is of great significance in assessing the effectiveness of regional eco-environmental governance and guiding future ecological environment construction. Compared to the soil erosion model at a small watershed scale in the Loess Plateau, research in NPP model in this area is less and should be further strengthened.

In this study, we built an NPP model at a small watershed scale in the Loess Plateau. In our model, particular attention was paid to the impact factors on the NPP in this region, including solar radiation and soil water that affect the process of plant transpiration and photosynthesis, and terrain that affects the redistribution of solar radiation and

\section{References}

Allen R G, Pereira L S, Raes D, et al. 1998. Crop Evapotranspiration-Guidelines for Computing Crop Water Requirements. Rome: soil water. Simulation results of the VPP model agreed with the observed mean values and simulation results of the VISM model developed for the Loess Plateau. The simulation and validation results indicate that the VPP model can be used to estimate the NPP of small watersheds in the region. Furthermore, the prediction showed the high consistency of NPP distribution with the land use map of the Yangou watershed, which indicates that vegetation type is the most important factor in determining the NPP distribution in small watersheds in the Loess Plateau. However, more measured NPP data and a further validation shall be aquired in other small watersheds of the Loess Plateau.

\section{Acknowledgements}

This research was financed by the Strategic Priority Research Program (XDA05050403) and the Key Research Program of Chinese Academy of Sciences (KZZD-EW-04). We thank the anonymous reviewers for their constructive and valuable comments and the editors for their responsible and patient work on the perfection of this paper.

Food and Agriculture Organization of the United Nations. Arneth A, Harrison S P, Zaehle S, et al. 2010. Terrestrial biogeochemi- 
cal feedbacks in the climate system. Nature Geoscience, 3(8): $525-532$.

Cramer W, Kicklighter D W, Bondeau A, et al. 1999. Comparing global models of terrestrial net primary productivity (NPP): overview and key results. Global Change Biology, 5(Suppl. 1): 1-15.

Farquhar G D, Von Caemmerer S, Berry J A. 1980. A biochemical model of photosynthetic $\mathrm{CO}_{2}$ assimilation in leaves of $\mathrm{C}_{3}$ species. Planta, 149(1): 78-90.

Fu B P. 1998. The differences and variations in components of radiation budget on underlying surfaces of different topographies. Scientia Atmospherica Sinica, 22: 178-190.

Gao Q, Reynolds J F. 2003. Historical shrub-grass transitions in the northern Chihuahuan desert: modeling the effects of shifting rainfall seasonality and event size over a landscape gradient. Global Change Biology, 9(10): 1475-1493.

He Y, Dong W J, Ji J J, et al. 2005. The net primary production simulation of terrestrial ecosystems in China by AVIM. Advances in Earth Science, 20(3): 345-349.

Huang Y M. 2003. Study on ecological aspects of water balance process at watershed level in hilly regions of the Loess Plateau, China: a case study in Zhifanggou watershed. Ph.D. Dissertation, Beijing: Beijing Normal University.

Li K R, Wang S Q, Cao M K. 2004. Vegetation and soil carbon storage in China. Science in China: Series D, 47(1): 49-57.

Li Y S. 2001. Effects of forest on water circle on the Loess Plateau. Journal of Natural Resources, 16(5): 427-432.

Li Z W, Cai Q G, Zeng G M. 2004. Regional simulation on land productivity in the Loess Plateau based on GIS and soil erosion. Resources Science, 26(21): 91-97.

Liu G B. 1999. Soil conservation and sustainable agriculture on the Loess Plateau: challenges and prospects. Ambio, 28(8): 663-668.

Liu J, Chen J M, Cihlar J, et al. 1997. A process-based boreal ecosystem productivity simulator using remote sensing inputs. Remote Sensing of Environment, 62(2): 158-175.

Liu J H. 2003. Spatial and temporal variation of soil moisture content and vegetation productivity at a small watershed of the Loess Plateau. MSc. Dissertation, Yangling: Northwest A \& F University, China.

Liu X Z, Kang S Z, Liu D L, et al. 2005. SCS model based on geographic information and its application to simulate rainfall-runoff relationship at typical small watershed level in Loess Plateau. Transactions of the Chinese Society of Agricultural Engineering, 21(5): 93-97.

Luo T X. 1996. Patterns of net primary productivity for Chinese major forest types and their mathematical models. Ph.D. Dissertation, Beijing: Chinese Academy of Sciences.

Melillo J M, McGuire A D, Kicklighter D W, et al. 1993. Global climate change and terrestrial net primary production. Nature, 363: 234-240.

Nemani R R, Keeling C D, Hashimoto H, et al. 2003. Climate-driven increases in global terrestrial net primary production from 1982 to
1999. Science, 300: 1560-1563.

Piao S L, Fang J Y, Zhou L M, et al. 2005. Changes in vegetation net primary productivity from 1982 to 1999 in China. Global Biogeochemical Cycles, 19(2): GB2027.

Piao S L, Ciais P, Friedlingstein P, et al. 2008. Net carbon dioxide losses of northern ecosystems in response to autumn warming. Nature, 451: 49-52.

Pimentel D. 2006. Soil erosion: a food and environmental threat. Environment, Development and Sustainability, 8(1): 119-137.

Potter C S, Randerson J T, Field C B, et al. 1993. Terrestrial ecosystem production: a process model based on global satellite and surface data. Global Biogeochemical Cycles, 7(4): 811-841.

Prioul J L, Chartier P. 1977. Partitioning of transfer and carboxylation components of intracellular resistance to photosynthetic $\mathrm{CO}_{2}$ fixation: a critical analysis of the methods used. Annals of Botany, 41(4): 789-800.

Shangguan Z P, Shao M A, Li Y S, et al. 2004. Impacts of forest vegetation on the soil water cycle in Loess Plateau. Journal of Chinese Soil and Water Conservation, 35: 177-185.

Wang L, Wang Q, Wei S, et al. 2008. Soil desiccation for loess soils on natural and regrown areas. Forest Ecology and Management, 255(7): 2467-2477.

Wu F Q, Zhou Z L, Liu H B. 2005. Productivity of crop-fruit ecological agriculture in middle-south Loess Plateau. Chinese Journal of Applied Ecology, 16(2): 262-266.

Xia Y Q, Shao M A. 2008. Soil water carrying capacity for vegetation: a hydrologic and biogeochemical process model solution. Ecological Modelling, 214(2-4): 112-124.

Xu H M, Jia H K, Huang Y M. 2005. A simulation model of net primary production at watershed scale in hilly area of Loess Plateau, China. Acta Ecologica Sinica, 25(5): 1064-1074.

Xu X, Gao Q, Liu Y H, et al. 2009. Coupling a land use model and an ecosystem model for a crop-pasture zone. Ecological Modelling, 220(19): 2503-2511.

Yang W Z, Shao M A. 2000. Study on Soil Moisture in the Loess Plateau. Beijing: Science Press.

Zeng Y, Qiu X, Liu C, et al. 2005. Distributed modeling of direct solar radiation on rugged terrain of the Yellow River basin. Acta Geographica Sinica, 60(4): 680-688.

Zhang N, Yu G R, Yu Z L, et al. 2003. Simulation of temporal and spatial distribution of natural vegetation light utilization efficiency based on 3S. Acta Phytoecologica Sinica, 27(3): 325-336.

Zheng F L. 2006. Effect of vegetation changes on soil erosion on the Loess Plateau. Pedosphere, 16(4): 420-427.

Zhou Y H, Xiang Y Q, Shan F Z. 1984. A climatological study on the photo-synthetically active radiation. Acta Meteorologica Sinica, 42: 387-397.

Zuazo V H D, Pleguezuelo C R R. 2008. Soil-erosion and runoff prevention by plant covers: a review. Agronomy for Sustainable Development, 28(1): 65-86. 